\title{
Tumefactive Inflammatory Diseases of the Pancreas
}

Yoh Zen* and Vikram Deshpande

From the Department of Diagnostic Pathology, ${ }^{*}$ Kobe University, Kobe, Japan; and The James Homer Wright Pathology Laboratories, ${ }^{\dagger}$ Massachusetts General Hospital, Boston, Massachusetts

Accepted for publication May 29, 2018.

Address correspondence to Vikram Deshpande, M.D., The James Homer Wright Pathology Laboratories, Massachusetts General Hospital, 55 Fruit St, Boston, MA 02114. E-mail: vdeshpande@mgh.harvard.edu.

\begin{abstract}
Advances in the past two decades have resulted in the recognition of several tumefactive pancreatic lesions that, on histologic evaluation, show a varying combination of inflammation and fibrosis. Autoimmune pancreatitis, the prototypic tumefactive pancreatic fibroinflammatory lesion, is composed of two distinct diseases, type 1 autoimmune pancreatitis and the less common type 2 autoimmune pancreatitis. Although designated as autoimmune pancreatitis, the two diseases show little morphologic or pathogenic overlap. In type 1 disease, subsets of T lymphocytes (type 2 helper $\mathrm{T}$ cells, regulatory $T$ cells, and $T$ follicular helper 2 cells) are hypothesized to drive the inflammatory reaction. The Bcell response is characterized by an oligoclonal expansion of plasmablasts, with dominant clones that vary among patients and distinct clones that emerge at the time of relapse. Although the precise role of IgG4 in this condition remains uncertain, recent studies suggest that other IgG subclasses (eg, IgG1) may mediate the immune reactions, whereas IgG4 represents a response to dampen excessive inflammation. A recent study of type 2 autoimmune pancreatitis highlights the role of CXCL8 (alias IL8), with duct epithelium and infiltrating $T$ lymphocytes expressing this chemokine; the latter may contribute to the distinct form of neutrophilic inflammation in this disease. The review also highlights other forms of mass-forming chronic pancreatitis: follicular pancreatitis, groove pancreatitis, and those associated with rheumatologic diseases. (Am J Pathol 2019, 189: 82-93; https://doi.org/10.1016/ j.ajpath.2018.05.022)
\end{abstract}

\section{History of Autoimmune Pancreatitis}

The term autoimmune pancreatitis was introduced in 1995 by Yoshida and coworkers, ${ }^{1}$ who described a steroidresponsive example of chronic pancreatitis. The presence of hyperglobulinemia and antinuclear antibodies and the steroid responsive nature of the disease alluded to a novel autoimmune disease. In retrospect, a few similar cases had been reported in the literature, and a French group is credited for the first description of autoimmune pancreatitis. $^{2}$ The 1991 description of this disease was the first detailed analysis of this entity: the study documents the clinical, radiological, and pathologic aspects of two patients who underwent surgical resection for suspected pancreatic cancer. ${ }^{3}$ Notably, the authors used the term lymphoplasmacytic sclerosing pancreatitis, an accepted synonym for type 1 autoimmune pancreatitis. Since these landmark articles, autoimmune pancreatitis has attracted significant attention because of its apparent idiopathic nature, unique pancreatic ductal changes, and a swift response to immunosuppressive agents. ${ }^{4-7}$ It was thus predicted (correctly) that the disease would account for a significant proportion of patients with idiopathic pancreatitis, particularly those lacking traditional risk factors for chronic pancreatitis.

A strong association between autoimmune pancreatitis and serum IgG4 elevation was noted in 2001 by Hamano and coworkers, ${ }^{8}$ an observation that dramatically accelerated the understanding of this disease and laid the foundation for the

\footnotetext{
Disclosures: None declared.

This article is a part of a review series on benign and neoplastic pancreatic lesions from their pathologic to molecular profiles and diagnoses.
} 
Table 1 Comparison of Type 1 and Type 2 Autoimmune Pancreatitis

\begin{tabular}{|c|c|c|}
\hline Variable & Type 1 autoimmune pancreatitis & Type 2 autoimmune pancreatitis \\
\hline Incidence, \% & Approximately 90 & Approximately 10 \\
\hline Age, years & $>40$ & Any age, including children \\
\hline Associated conditions & $\begin{array}{l}\text { IgG4-related disease (eg, cholangitis, } \\
\text { sialadenitis, dacryoadenitis, retroperitoneal } \\
\text { fibrosis, interstitial nephritis, and periaortitis) }\end{array}$ & $\begin{array}{l}\text { Inflammatory bowel disease, particularly } \\
\text { ulcerative colitis }\end{array}$ \\
\hline \multicolumn{3}{|l|}{ Microscopic findings } \\
\hline Lymphoplasmacytic infiltration & Common & Common \\
\hline Irregular fibrosis & Common & Common \\
\hline Storiform fibrosis & Common & Rare \\
\hline Obliterative phlebitis & Common & Rare \\
\hline IgG4/IgG-positive cell ratio, $\%$ & $>40$ & $<40$ \\
\hline Steroid responsiveness & Good & Good \\
\hline Relapse, $\%$ & $30-50$ & $<5$ \\
\hline Suspected immune reactions & $\begin{array}{l}\text { Th2-shifted reaction; activated regulatory T cells; } \\
\text { increased T follicular helper } 2 \text { cells; expanded } \\
\text { plasmablasts; infiltration of M2-type } \\
\text { macrophage }\end{array}$ & $\begin{array}{l}\text { Aberrant CXCL8/IL-8 expression in the duct } \\
\text { epithelium; infiltration of CXCL8/IL-8-positive } \\
T \text { cells }\end{array}$ \\
\hline
\end{tabular}

HPF, high-power field; Th2, type 2 helper T cell.

recognition of IgG4-related disease. In this cohort of 20 patients with sclerosing pancreatitis, a serum IgG4 cutoff at 135 $\mathrm{mg} / \mathrm{dL}$ appeared to be a highly accurate diagnostic marker for autoimmune pancreatitis, discriminating this disease from usual chronic pancreatitis and pancreatic cancers with a sensitivity and specificity of $>90 \% .^{8}$ The authors also demonstrated IgG4-positive plasma cells at affected sites, suggesting that these plasma cells represent the source of the serum immunoglobulin. ${ }^{9}$ Subsequent investigators identified IgG4-rich lymphoplasmacytic infiltrates in patients with idiopathic extrapancreatic fibrosing diseases at a wide range of anatomic sites, including the bile duct, ${ }^{10,11}$ salivary gland, ${ }^{12,13}$ lacrimal gland, ${ }^{14}$ lungs, ${ }^{15}$ kidney, ${ }^{16}$ and retroperitoneum, ${ }^{17-19}$ eventually leading to the concept of systemic IgG4-related disease. ${ }^{20,21}$

According to a recent study on 235 consecutive patients with IgG4-related disease, autoimmune pancreatitis is the leading manifestation, affecting $60 \%$ of patients, followed by sialadenitis (34\%), interstitial nephritis (23\%), dacryoadenitis (23\%), and periaortitis (20\%). ${ }^{22}$ Interestingly, 95\% of patients with IgG4-related disease show at least one of these five manifestations. ${ }^{22}$

\section{Autoimmune Pancreatitis}

\section{Evolution of Two Distinct Diseases}

Several large series confirmed the consistent presence of dense lymphoplasmacytic infiltration, irregular fibrosis, and acinar atrophy in autoimmune pancreatitis; however, a subset of cases showed a distinct appearance, one characterized by a neutrophil-rich infiltrate. ${ }^{23,24}$ This latter group, composed of younger individuals, showed a high incidence of inflammatory bowel disease. ${ }^{23}$ Patients with neutrophil-rich disease also showed fewer IgG4-positive plasma cells. ${ }^{25}$ The two competing hypotheses generated a robust discussion among pancreatophiles: neutrophil-rich cases represent an early/ active phase of autoimmune pancreatitis, and these patients represent a distinct and unrelated disease. Eventually, an international effort led to the recognition of two etiologically distinct forms of autoimmune pancreatitis ${ }^{26-28}$ : type 1 (IgG4related) and type 2 (neutrophil-rich) autoimmune pancreatitis (Table 1). ${ }^{29,30}$ The former constitutes the pancreatic manifestation of systemic IgG4-related disease, whereas the latter is unrelated to IgG4-related disease.

Although widely accepted by the pancreatic world, this classification may appear perplexing because of the use of virtually identical terms to designate two distinct diseases. The clinicopathologic features of the two diseases differ considerably, and the autoimmune nature of type 2 pancreatitis remains doubtful. The term type 2 autoimmune pancreatitis is the legacy of an era in which the understanding of autoimmune pancreatitis was in its infancy. In an attempt to draw a clear distinction between the two diseases, some investigators support terms that predate the recognition of IgG4-related disease: idiopathic duct-centric pancreatitis instead of type 2 autoimmune pancreatitis. ${ }^{31}$ According to one international multicenter study, type 1 disease accounts 
for $>90 \%$ of all patients diagnosed with autoimmune pancreatitis. ${ }^{32}$ Significant geographic differences exist in the prevalence of type 2 disease, and it is suspected to be less common in Asia, a pattern similar to inflammatory bowel disease, which is also more frequently diagnosed in the West.

\section{Etiopathogenesis and Mechanistic Aspects}

Type 1 Autoimmune Pancreatitis

Similar to other immune-mediated conditions, the exposure of genetically susceptible individuals to environmental or intrinsic risk factors triggering a stereotypical orchestral immune reaction represents a likely pathogenetic mechanism for type 1 autoimmune pancreatitis. ${ }^{31}$ The strongest genetic risk relates to $H L A,{ }^{33}$ with minor associations involving polymorphisms of immune-related genes (eg, CTLA4 and FCRL3). ${ }^{34,35}$ Autoimmunity has been suspected as an immunologic trigger, chiefly because autoantibodies are detected in approximately $40 \%$ of patients, ${ }^{36,37}$ although multiple efforts have failed to identify a disease-specific autoantibody. ${ }^{36}$ Most proposed autoantibodies recognize pancreatic enzymes or secretory proteins (antilactoferrin in 13 of 17 cases; anti-carbonic anhydrase II in 10 of 17 cases), but they are not entirely specific for this condition. ${ }^{36-38}$ In addition, unlike most other typical autoimmune diseases, type 1 autoimmune pancreatitis affects elderly men. Other hypotheses that are either unproved or lack validation include chronic exposure to chemicals or microbes, allergic reactions, and paraneoplastic syndrome. ${ }^{39-41}$ Suspected immune reactions to yet to be identified antigens are schematically summarized in Figure 1.

Early studies of type 1 autoimmune pancreatitis emphasize the role of T cells. ${ }^{36}$ On the basis of the repertoire of T-cell subsets infiltrating the pancreas and differential expression of cytokines, the disease is hypothesized to show a type 2 helper T-cell bias. ${ }^{42}$ In theory, type 2 helper T-cell cytokines, such as

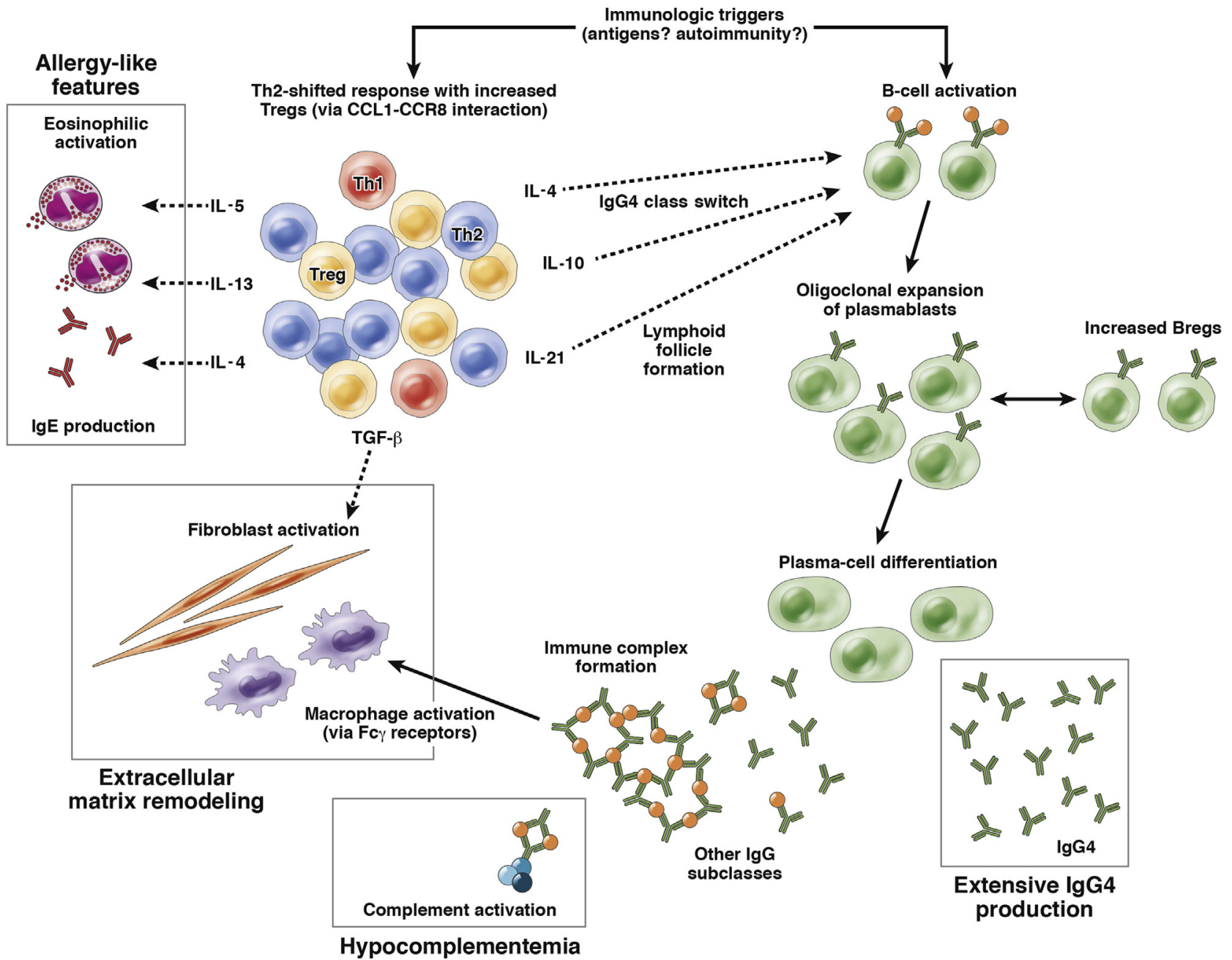

Figure 1 Proposed immunologic interactions in type 1 autoimmune pancreatitis. Type 2 helper T-cell (Th2)-shifted T-cell response is associated with various clinical and pathologic features, including eosinophilia and IgE production. T-cell reactions also drive B-cell activation, leading to the oligoclonal expansion of plasmablasts. IgG4 is supposedly secreted to dampen excessive inflammation, whereas other IgG subclasses probably contribute to the following fibroinflammatory responses, including macrophage activation and complement fixation. Adapted from Hart et al, ${ }^{31}$ with permission from Elsevier Inc. Breg, $\mathrm{B}$ regulatory cell; $\mathrm{CCL}$, chemokine (C-C motif) ligand; TGF- $\beta$, transforming growth factor- $\beta$; Th1, type 1 helper T cell; Treg, $\mathrm{T}$ regulatory cell. 
IL-4, IL-5, and IL-13, contribute to tissue and/or serum eosinophilia and elevated serum IgE levels, findings often observed in patients with type 1 autoimmune pancreatitis. ${ }^{43}$ However, the type 1 helper T-cell reaction is not fully suppressed and occasional T cells express interferon- $\gamma$, the latter a defining feature of type 1 helper T-cell bias. Unlike classic autoimmune diseases in which regulatory immune pathways are suppressed, autoimmune pancreatitis shows an increased proportion of regulatory $\mathrm{T}$ cells, within both tissue and peripheral blood. ${ }^{42,44}$ IL-10, produced by regulatory $\mathrm{T}$ cells, may guide IgG4 class switch; the combination of IL-4 and IL10 enhances production of IgG4 from B cells and plasma cells. $^{45}$ However, IgG4 class switch also requires the involvement of other lymphocyte subsets, such as T follicular helper (Tfh) cells. Recent studies have also implicated oligoclonal $\mathrm{CD}^{+}{ }^{+}$cytotoxic $\mathrm{T}$ cells that secrete of interferon- $\gamma$, IL- $1 \beta$, and transforming growth factor- $\beta$. $^{46}$

Recent studies on IgG4-related sialodacryoadenitis postulate critical roles for Tfh cells in IgG4-related disease. ${ }^{47,48} \mathrm{Tfh}$ cells, a distinct subset of CD4-positive helper T cells, are involved in germinal center formation, B-cell differentiation, and antibody maturation ${ }^{49}$; these processes are partly mediated by IL- 4 and IL-21 produced by Tfh cells. This specialized T-cell subset is characterized by expression of B-cell lymphoma 6 and $\mathrm{C}-\mathrm{X}-\mathrm{C}$ chemokine receptor 5; the latter protein assists in the migration of Tfh cells through an interaction with CXCL13 expressed by follicular stromal cells. ${ }^{49}$ Among Tfh subsets (eg, Tfh1, Tfh2, and Tfh17), circulating Tfh2 cells are preferentially expanded in IgG4-related disease, with their quantities positively correlating with the number of affected organs, disease activity scores, and serum IgG4 levels. ${ }^{4,48}$ An in vitro study supports the direct involvement of Tfh2 cells in IgG4 class switch: co-cultured autologous naïve B cells and Tfh cells derived from patients with IgG4-related disease, but not Tfh 1 and Tfh 17 cells, induce IgG4 production. ${ }^{48}$ This form of $\mathrm{T}$ cell-B cell interaction is postulated to occur within lymphoid follicles, although lymphoid follicles with germinal centers are less common in type 1 autoimmune pancreatitis than IgG4-related sialodacryoadenitis $(<10 \%$ versus $>50 \%) .{ }^{50}$ Therefore, the location of the IgG4 class switch in type 1 autoimmune pancreatitis remains uncertain.

The role of B cells in the pathogenesis of type 1 autoimmune pancreatitis was reinforced by an observation that B-cell depletion therapy with anti-CD20 antibodies is highly effective for type 1 autoimmune pancreatitis. ${ }^{51}$ The expanded plasmablast population in patients with IgG4-related disease, a precursor of plasma cells, shrinks rapidly on treatment. ${ }^{52}$ The increased plasmablasts are mainly of the IgG4 type. An analysis of the plasmablast B-cell receptor repertoire also noted the oligoclonal nature of this expansion. ${ }^{52}$ Another similar study validated the oligoclonal nature of tissueresident and circulating IgG4-switched B cells in type 1 autoimmune pancreatitis. ${ }^{53}$ Interestingly, the dominant clones vary between patients, and novel clones emerge on relapse, weakening the hypothesis that IgG4-bearing cells represent the driver mechanism in autoimmune pancreatitis. ${ }^{52}$
In addition, IgG4 is generally regarded as a noninflammatory antibody because of its relative inability to fix complement and its limited capacity to bind Fc receptors. ${ }^{54} \mathrm{~A}$ conformational change accounts for its anti-inflammatory nature, the so-called Fab-arm exchange, wherein a pair of heavy and light chains are exchanged between two IgG4 antibody molecules. ${ }^{55}$ As a result of the unusual structural alteration, the antibody loses its ability to cross-link antigens and consequently to form large immune complexes. In addition to this noninflammatory configuration, exhaustive efforts have failed to identify IgG4-type autoantibodies. Collectively, these studies have prompted many investigators to suspect that $\mathrm{IgG} 4$ may be secondarily induced in type 1 autoimmune pancreatitis, in an attempt to dampen excess inflammatory reaction.

A recent murine model lends credence to this hypothesis: neonatal mice subcutaneously injected with circulating IgG from patients with type 1 autoimmune pancreatitis ${ }^{56}$ developed pancreatic injury, with stromal edema, acinar necrosis, hemorrhage, and infiltration of polymorphonuclear leukocytes. $^{55}$ However, tissue destruction induced by IgG1 was suppressed by the simultaneous injection of patient-derived IgG4. ${ }^{56}$ This model suggests that non-IgG4 antibodies, particularly $\mathrm{IgG} 1$, are proinflammatory, whereas $\mathrm{IgG} 4$ induction represents a secondary and potentially protective anti-inflammatory reaction. The IgG1-driven hypothesis may also explain hypocomplementemia, often seen in patients with type 1 autoimmune pancreatitis, an otherwise counterintuitive phenomenon given the relative inability of IgG4 to fix complements.

A nonbiased proteomics approach that compared IgG4related cholangitis with primary sclerosing cholangitis ${ }^{57}$ identified three immunologic pathways activated in IgG4related disease. ${ }^{57}$ The most notable pathway was $\mathrm{Fc}-\gamma$ receptor-mediated phagocytosis. Given the weak binding capacity of IgG4 to Fc- $\gamma$ receptors, Igs activating this signal cascade are more likely triggered by other IgG subclasses. The $\mathrm{Fc}-\gamma$ receptor-mediated pathway generally leads to macrophage activation. ${ }^{57}$ Immunostaining demonstrates extensive infiltration of M2-type macrophages in type 1 autoimmune pancreatitis. ${ }^{57}$ The macrophages infiltrate the collagen, assume a spindled configuration, and may contribute to the storiform pattern of fibrosis.

\section{Type 2 Autoimmune Pancreatitis}

Although immunologic aspects of this form of pancreatitis are largely unknown, a clue to the etiology lies in the observation that one-third of patients report inflammatory bowel disease, particularly ulcerative colitis. ${ }^{58}$ The more common pancreaticobiliary disease associated with inflammatory bowel disease, primary sclerosing cholangitis, lacks a relationship with type 2 autoimmune pancreatitis. In addition, unlike type 2 autoimmune pancreatitis, primary sclerosing cholangitis is resistant to steroids. Therefore, etiologic parallels cannot be drawn between primary sclerosing cholangitis and type 2 autoimmune pancreatitis. 

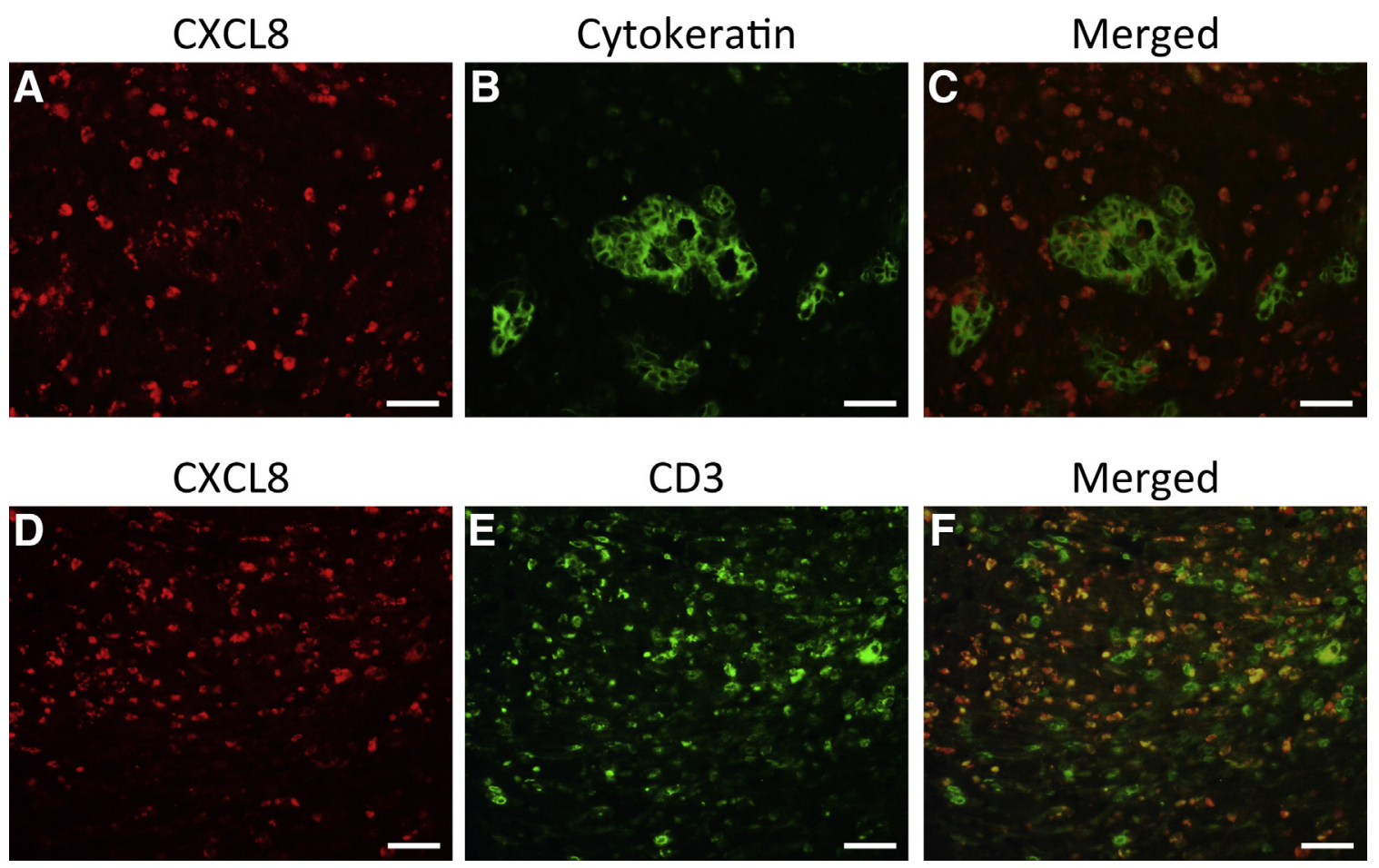

Figure 2 CXCL8 expression in type 2 autoimmune pancreatitis. Double staining demonstrates pancreatic ductal cells double positive for CXCL8 and cytokeratin (A-C) and infiltrating lymphocytes positive for CXCL8 and CD3 (D-F). Double immunostaining was performed manually using primary antibodies against IL-8 (clone number 6217; R\&D Systems, Minneapolis, MN), wide spectrum cytokeratin (clone ab9377; Abcam, Cambridge, UK), and CD3 (clone SP7; Abcam). The reaction product was visualized with Alexa Fluor fluorescent antibodies 488 (green) and 594 (red) (Thermo Fisher Scientific, Waltham, MA). Scale bars $=50 \mu \mathrm{m}(\mathbf{A}-\mathbf{F})$.

A recent study of cytokine expression in pancreatic tissue samples from patients with type 2 autoimmune pancreatitis ${ }^{59}$ revealed almost undetectable levels of IL4, IL10, and TNFA mRNA, highlighting the immunologic differences between the two forms of autoimmune pancreatitis. ${ }^{59}$ The expression of INFG mRNA was comparable between types 1 and 2 autoimmune pancreatitis, whereas higher expression of CXCL8 (alias IL-8) mRNA was observed in type 2 disease, 13-fold higher than type 1 disease. ${ }^{59}$ On immunostaining, the major source of CXCL8 appeared to be neutrophils, T cells, and damaged duct/ductular epithelium (Figure 2). ${ }^{59}$ CXCL8positive cells were scarce in type 1 autoimmune pancreatitis. CXCL8 expression was also seen in pancreatitis adjacent to a neoplasm, albeit largely restricted to infiltrating neutrophils. CXCL8, a known chemotactic factor for neutrophils, may trigger migration of neutrophils and account for the characteristic form of injury, granulocytic epithelial lesion. ${ }^{59}$ Similarly, CXCL8-expressing T cells may also contribute to recruitment of neutrophils.

The expression of CXCL8 in inflammatory bowel disease, specifically the colonic epithelial cells with crypt abscesses, was another notable finding. ${ }^{59}$ Although neutrophilic infiltration is common in infectious colitis, crypt epithelium in this form of colitis was virtually negative for CXCL8. Taken together, these findings suggest that type 2 autoimmune pancreatitis and ulcerative colitis share common immunologic pathways, with neutrophilic epithelial injury representing one link between the two conditions. A single difference observed in that study was that CXCL8-positive T cells were present in type 2 autoimmune pancreatitis but not identified in ulcerative colitis.

\section{Clinical Features}

Type 1 autoimmune pancreatitis predominantly affects elderly male patients (mean age at diagnosis, 64 years), with a male/female ratio of $3: 1{ }^{60-64}$ Nevertheless, the disease also affects women, and there are several well-characterized examples of autoimmune pancreatitis in children, although most of them are suspected to be type $2 .{ }^{65,66}$ The most common clinical presentation is painless obstructive jaundice; thus, the initial diagnosis is often pancreatic adenocarcinoma. ${ }^{60-63}$ Less common modes of presentation include an incidentally detected pancreatic mass lesion on cross-sectional imaging and, rarely, acute pancreatitis. The nonpancreatic manifestations could overshadow pancreatic disease, and some patients may present initially with palpable mass lesions, such as submandibular gland enlargement. Type 1 autoimmune pancreatitis is the pancreatic manifestation of IgG4-related disease, and most patients eventually develop fibroinflammatory diseases at other locations, such as the hepatobiliary system, retroperitoneum, kidney, salivary glands, orbit, lymph nodes, among others. ${ }^{20}$ 
Type 2 autoimmune pancreatitis affects a younger population; the mean age ranged from 30 to 52 years. ${ }^{5,62,67}$ Patients with type 2 autoimmune pancreatitis typically present with acute pancreatitis; these patients are less likely to be mistaken for having pancreatic adenocarcinoma. ${ }^{58}$ Less frequently, the symptoms and signs may overlap with type 1 autoimmune pancreatitis (ie, painless obstructive jaundice). Type 2 disease is confined to the pancreas, with one major caveat, between $20 \%$ and $44 \%$ of patients report a history of inflammatory bowel disease. ${ }^{58,62}$

\section{Imaging}

The diffusely enlarged pancreas often assumes a sausageshaped appearance. ${ }^{68} \mathrm{~A}$ low-attenuating peripancreatic capsule-like rim, the so-called saran-wrap sign, represents another characteristic radiological feature of autoimmune pancreatitis. ${ }^{60,68}$ Some cases show a focal mass-like enlargement, an appearance that may closely mimic pancreatic ductal adenocarcinoma. Notably, type 2 autoimmune pancreatitis is more likely to show a mass lesion. ${ }^{58}$

Diffuse or segmental narrowing of the main pancreatic duct on magnetic resonance cholangiopancreatography or endoscopic retrograde cholangiopancreatography is a characteristic feature of autoimmune pancreatitis; a dilated main pancreatic duct is distinctly uncommon. ${ }^{69}$ Collectively, the presence of an enlarged pancreas and narrow main pancreatic duct, with or without extrapancreatic manifestations of IgG4-related disease, often provides compelling evidence of autoimmune pancreatitis, obviating the need to biopsy the pancreas.

\section{Pathology}

Although both forms of pancreatitis are characterized by fibrosis and inflammation, the pathologic features of the two variants differ significantly, thus allowing for the relatively straightforward distinction between type 1 and type 2 autoimmune pancreatitis.

\section{Type 1 Autoimmune Pancreatitis}

Type 1 autoimmune pancreatitis, a prototypic IgG4-related disease, shows the histologic hallmarks of this fibroin-

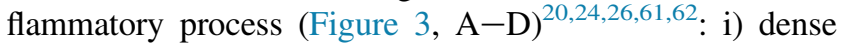
lymphoplasmacytic infiltrate, ii) storiform-type fibrosis, and iii) obliterative phlebitis. ${ }^{70}$ Although a mass-like lesion is often observed on imaging, a well-defined tumor is seldom seen on gross evaluation. Histologically, the diseased pancreas shows a lymphoplasmacytic infiltrate with a sprinkling of eosinophils; neutrophils are notably scarce or absent. ${ }^{20,61,62,70,71}$ Unafffected regions of pancreas are not
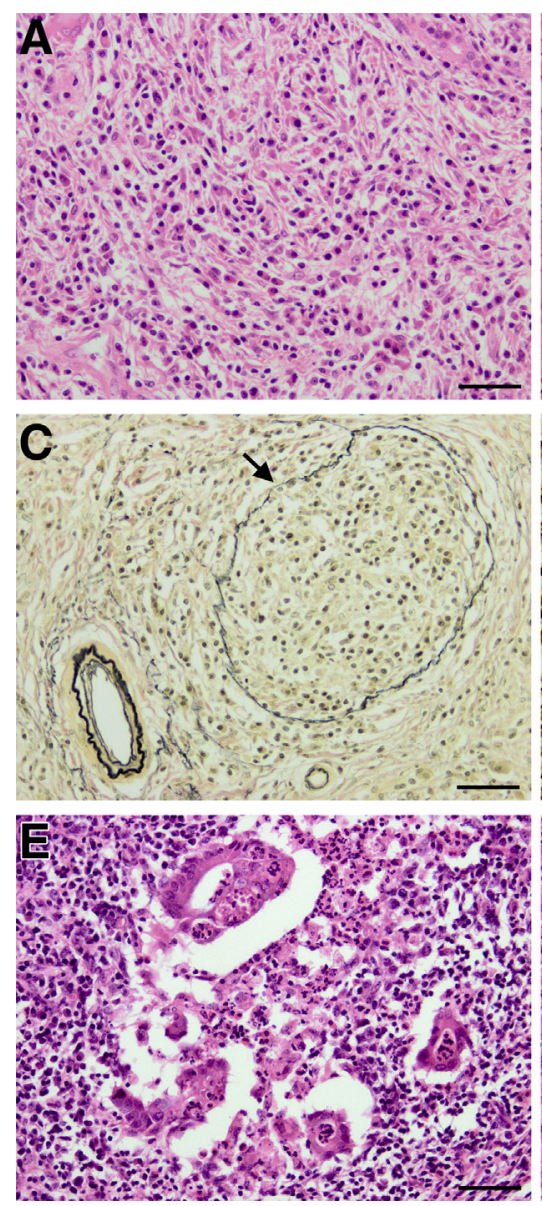
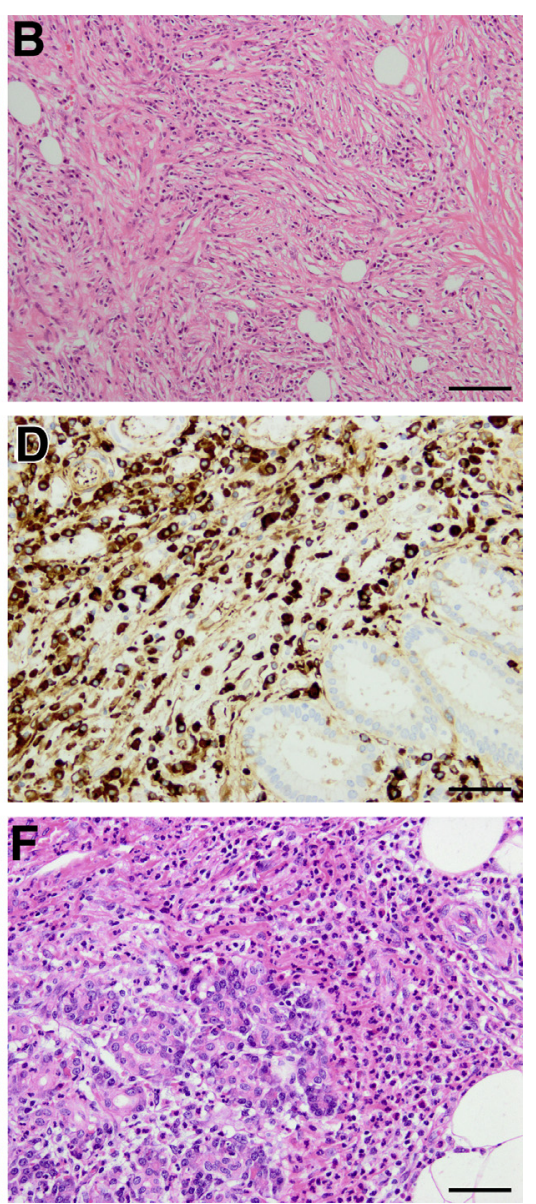

Figure 3 Histologic features of autoimmune pancreatitis. Type 1 autoimmune pancreatitis shows dense lymphoplasmacytic infiltration (A), storiform fibrosis (B), obliterative phlebitis (arrow highlights focus of obliterative phlebitis; C), and extensive infiltration of IgG4-positive plasma cells (D). In type 2 autoimmune pancreatitis, many neutrophils infiltrate the pancreatic duct $(\mathbf{E})$ and lobule $(\mathbf{F})$. Staining included hematoxylin and eosin staining (A, B, E, and $\mathbf{F}$ ), elastica van Gieson staining (C), and IgG4 immunostaining (D). Scale bars: 50 $\mu \mathrm{m}$ (A and $\mathbf{C}-\mathbf{F}) ; 100 \mu \mathrm{m}$ (B). 
uncommon. Although inflammation and fibrosis distort the pancreatic architecture, the lobular pattern, a feature of a benign pancreatic disease, is preserved. The pancreatic lobules are inflamed and the disease is associated with significant loss of acinar tissue; islets are typically preserved. ${ }^{72}$ The interlobular septa are greatly expanded, and storiform-type fibrosis, a cart-wheel type pattern of fibrosis, is best appreciated at this site. Obliterative phlebitis, also localized to the interlobular septa, can be subtle, and an elastic stain is often necessary to uncover these partially or completely obliterated veins. Although the pancreas is intensely inflamed, the pancreatic ducts are generally preserved, with no histologic evidence of injury. Involvement of the intrapancreatic portion of the bile duct is common. ${ }^{73}$ Characteristically, the fibroinflammatory infiltrate involves the entire thickness of the bile duct.

\section{Type 2 Autoimmune Pancreatitis}

The principal difference between type 2 and type 1 autoimmune pancreatitis is the neutrophil-rich infiltrate in the former disease. ${ }^{24,26,61,62}$ Characteristically, clusters of neutrophils are identified within ducts, the hallmark of type 2 disease, aptly designated granulocytic epithelial lesion (Figure 3E). ${ }^{23,61,62}$ These intraductal abscesses are remarkably similar to those seen in inflammatory bowel disease. Intra-acinar neutrophils often accompany intraductal abscesses (Figure 3F). In a proportion of cases, the ductal injury is more intense, culminating in ulceration of the epithelium. Periductal lymphoplasmacytic accentuation is a characteristic feature of type 2 autoimmune pancreatitis. Obliterated veins are seldom identified, although more subtle forms of phlebitis may be seen.

\section{Immunophenotype}

As with many inflammatory diseases, $\mathrm{T}$ lymphocytes dominate the inflammatory milieu.

The most striking immunophenotypic difference between the two forms of autoimmune pancreatitis lies in the distribution and number of IgG4-positive plasma cells. The pancreatic manifestation of IgG4-related disease, type 1 autoimmune pancreatitis, shows a diffuse increase in IgG4positive plasma cells (Figure 3D). The cut point suggested by most guidelines is 10 per high-power field in biopsy material and 50 per high-power field on resection samples. ${ }^{29}$ An $\mathrm{IgG} / \mathrm{IgG}$ ratio of $>40 \%$ strongly supports a diagnosis of type 1 autoimmune pancreatitis. ${ }^{70}$ Type 2 autoimmune pancreatitis typically lacks this marked increase in IgG4positive plasma cells, although isolated pockets of positive cells are not uncommon.

It should be emphasized that the presence of IgG4-positive cells is neither specific nor a highly sensitive marker of type 1 autoimmune pancreatitis. ${ }^{74}$ Of particular concern is the peritumoral increase in IgG4-positive plasma cells in pancreatic ductal adenocarcinomas. Similarly, intraductal and intralobular neutrophils do not unequivocally distinguish pancreatic ductal adenocarcinoma from type 2 autoimmune pancreatitis. ${ }^{59}$ Furthermore, type 1 autoimmune pancreatitis may lack IgG4positive plasma cells, the so-called IgG4-negative IgG4related disease. $^{75}$

\section{Diagnosis}

The diagnosis of autoimmune pancreatitis should be adjudicated only after a thorough workup to exclude a pancreatic neoplasm. The overarching goal of this effort is to avert a pancreatic resection; optimal therapy requires immunosuppression, and a pancreatic resection is generally contraindicated. The histologic features alluded to above would also apply to core needle biopsy specimens; however, the limited sample size presents additional challenges. The current diagnostic algorithm is based on two existing realities: clinically and radiologically autoimmune pancreatitis may prove indistinguishable from pancreatic adenocarcinoma, and the incidence of autoimmune pancreatitis is significantly lower than that of pancreatic adenocarcinoma. Iterative attempts to codify the distinction between autoimmune pancreatitis and pancreatic adenocarcinoma have evolved into an internationally accepted algorithm, ${ }^{29,76}$ one predicated on five features: i) imaging, ii) serology, iii) other organ involvement, iv) histopathology, and v) favorable response to steroids.

An elevated serum IgG4 remains the only reliable serologic parameter, albeit with several notable caveats. An elevated serum IgG4 is neither highly sensitive nor specific: the sensitivity is reported to range from $60 \%$ to $80 \%$, and approximately $10 \%$ of pancreatic ductal adenocarcinomas show an elevated serum IgG4 ${ }^{77,78}$ Nevertheless, an IgG4 level two times the upper limit of normal is highly suggestive of autoimmune pancreatitis and is only rarely observed in pancreatic adenocarcinoma. ${ }^{77}$ Involvement of other organs, both synchronous or metachronous, particularly those characteristically involved by IgG4-related disease, provides strong supportive evidence. Concurrent evidence of sclerosing cholangitis could be virtually diagnostic of autoimmune pancreatitis. And finally, often used only as a last resort, a trial of steroids may be used to distinguish autoimmune pancreatitis from pancreatic ductal adenocarcinoma. The lack of a swift response to steroids should prompt another thorough evaluation to exclude malignancy, one that could include a repeated biopsy. ${ }^{24,26,61,62}$ Histopathology may play a largely supportive role in the diagnosis of type 1 autoimmune pancreatitis.

Conversely, the diagnosis of type 2 autoimmune pancreatitis is predicated on a combination of four cardinal features: i) imaging, ii) ulcerative colitis, iii) histopathology of the pancreas, and iv) response to steroid therapy. ${ }^{58}$ Relative to type 1 autoimmune pancreatitis, type 2 disease is more reliant on documenting histopathologic changes. In the absence of inflammatory bowel disease, a definitive diagnosis of type 2 disease can only be made if a granulocytic epithelial lesion is identified. However, it is emphasized that neutrophils may be 
noted both adjacent to and within pancreatic ductal adenocarcinomas.

\section{Treatment and Outcome}

Although most patients with autoimmune pancreatitis require some form of immunosuppressive therapy, rarely, patients show spontaneous resolution of their lesion. Induction therapy with steroids remains the first-line agent for patients with active untreated autoimmune pancreatitis. ${ }^{76,79}$ In an international multicenter study for autoimmune pancreatitis, steroids achieved remissions in $99 \%$ of patients with type 1 autoimmune pancreatitis and in $92 \%$ of patients with type 2 autoimmune pancreatitis. ${ }^{79}$ A favorable response on imaging is typically seen 2 weeks after initiating steroids. This high-dose induction therapy is typically administered for 4 weeks. In patients demonstrating remission or at least significant radiological and biochemical improvement in target organ inflammation, steroids are tapered every 1 to 2 weeks.

A notable feature of type 1 autoimmune pancreatitis is the relapsing-remitting nature of this condition. The disease relapses in $30 \%$ to $50 \%$ of patients with type 1 autoimmune pancreatitis. The efficacy of low-dose steroids as maintenance therapy to prevent relapses remains controversial. Maintenance of remission therapy should be considered in selected cases at higher risk of recurrence: i) high serum IgG4 levels (such as greater than four times the upper limit of normal) before treatment, ii) persistently high serum IgG4 levels after steroid treatment, iii) diffuse enlargement of the pancreas, iv) concurrent involvement of the proximal portion of the bile duct (IgG4related sclerosing cholangitis), and v) extensive multiorgan involvement. Maintenance therapy often consists of low-dose steroids ( 2.5 to $10 \mathrm{mg} /$ day) for 1 to 3 years. To reduce the cumulative risk of adverse effects associated with long-term glucocorticoid treatment, steroid-sparing agents (eg, azathioprine, mycophenolate mofetil, methotrexate, and cyclophosphamide) have been used to maintain disease remission.

In a proportion of cases, glucocorticoid monotherapy fails to induce remission. In this scenario, rituximab, a monoclonal CD20 antibody, can induce remission as a single agent. $^{51}$ In patients in whom steroids are contraindicated, rituximab represents an alternative to steroids as a form of induction as well as maintenance therapy.

Finally, some studies have suggested that patients with autoimmune pancreatitis may show an elevated risk of pancreatic malignancy. ${ }^{41,80}$ Although the risk of malignancy in this disease remains controversial, in practice, the possibility of malignancy should be entertained when an intrapancreatic mass lesion, both de novo and recurrent, fails to show a favorable response to immunosuppressive agents: primary nonresponse to steroid therapy is extremely unusual in autoimmune pancreatitis. Some patients may develop pancreatic exocrine insufficiency. ${ }^{78}$

Type 2 autoimmune pancreatitis also shows a favorable response to steroids; maintenance therapy is generally not required because relapses are uncommon.

\section{Other Uncommon Forms of Tumefactive Pancreatitis}

\section{Groove Pancreatitis}

This form of pancreatitis was initially recognized in the 1970s, and there remain significant uncertainties with regard to its etiology. Like many forms of pancreatitis, this disease mimics pancreatic carcinoma. Several alternative terms have been used to designate this disease, including paraduodenal pancreatitis, cystic dystrophy of the heterotopic pancreas, myoadenomatosis of duodenal wall, and paraduodenal wall cyst; each term emphasizes a particular anatomic or histologic facet of the disease. The term groove pancreatitis highlights the epicenter of the disease: the groove of the duodenum with pancreas. The disease typically affects men in their fifth decade of life.

The diagnosis of groove pancreatitis is based on two broad principles: the epicenter of the disease is at the duodenal-pancreatic interface, and an alternative diagnosis is excluded, particularly autoimmune pancreatitis. The diagnosis thus relies significantly on the macroscopic appearance. Characteristic macroscopic pathology includes the following: i) localization of the fibrosing pathology to the region of the accessory pancreatic duct, with the latter located $2 \mathrm{~cm}$ proximal to the opening of the main pancreatic duct; ii) granular and nodular duodenal mucosa, particularly adjacent to the accessory pancreatic duct; iii) thickening of the duodenal muscle layer, often associated with cystic change; and iv) limited extension into the pancreas. Relative to the macroscopic appearance, the microscopic features are far often less impressive. Prominent Brunner gland, myoid hyperplasia in the duodenal wall, and cysts lined by granulation constitute the most obvious findings. The underlying pancreas shows fibrosis. Dilated ducts filled with inspissated material, similar to that observed with alcohol-related pancreatitis, is often seen.

The current hypothesis regarding the etiology relies on the location of the disease: dysfunction of the accessory pancreatic duct, although there are no functional data to support this hypothesis. There is a strong correlation between groove pancreatitis and a history of alcoholism and gallstone disease.

\section{Follicular Pancreatitis}

This uncommon form of idiopathic pancreatitis is underrecognized, with only sporadic case reports and small case series. ${ }^{81-83}$ Although the term follicular pancreatitis was first used in 2012, ${ }^{83}$ similar cases had been reported under the terms pancreatic pseudolymphoma and reactive lymphoid hyperplasia. ${ }^{84,85}$ The disease typically affects older adults, $>50$ years of age, with a slight male predominance (60\%). Unlike autoimmune pancreatitis, half of all patients are asymptomatic and are identified on cross-sectional imaging. ${ }^{81,83}$ The masslesion mimics a pancreatic neoplasm, although pancreatic 
duct dilatation resembling intraductal papillary mucinous neoplasm has also been described. Histologically, a characteristic finding is extensive lymphoid follicle formation, particularly around pancreatic ducts. ${ }^{81,83,86}$ The follicularpattern inflammation, to a variable degree, also involves pancreatic parenchyma. Despite severe periductal inflammation, follicular pancreatitis lacks evidence of pancreatic duct injury. Infiltrating cells are predominantly lymphocytes; plasma cells, although present, are fewer than seen in autoimmune pancreatitis. The general absence of storiform fibrosis and obliterative phlebitis is notable. IgG4-positive plasma cells are sparse, and the IgG4/IgG-positive plasma cell ratio is $<40 \%$.

Although most reported cases were diagnosed by the histologic examination of the resected pancreas, one case was successfully treated conservatively with steroids, with a $50 \%$ reduction in the size of the pancreatic mass. ${ }^{81}$ The etiology of follicular pancreatitis remains unclear. Patients usually lack serologic features of autoimmune disease or history of other inflammatory conditions, although a single patient reported ulcerative colitis. ${ }^{81}$ Interestingly, similar lymphoid follicle-rich inflammation may involve hilar bile ducts (follicular cholangitis) and gallbladder (follicular cholecystitis).$^{83}$ Consequently, this condition may belong to a spectrum of a follicular-pattern pancreaticobiliary disease. We also recently observed patients with pancreatic carcinoma with a follicular pancreatitis-like pattern of injury involving the upstream pancreas, alluding to the multifactorial etiology of follicular pancreatitis and a stereotypical response to multiple triggers.

\section{Pancreatic Involvement in Systemic Conditions}

The pancreas is uncommonly affected by systemic inflammatory conditions. Granulomatosis with polyangiitis, formally known as Wegener granulomatosis, may exhibit mass-forming pancreatitis or acute pancreatitis. ${ }^{87-89}$ In patients with extensive systemic disease, the diagnosis is straightforward; however, patients with isolated pancreatic involvement may pose a diagnostic challenge. We have observed several such patients, who required pancreatic resection for suspected malignancy. On biopsy, the diagnosis of granulomatosis with polyangiitis may be difficult, particularly in those patients with a low index of suspicion. Diagnostic clues for granulomatosis with polyangiitis include dirty necrosis, palisading granulomas, and vasculitis. A notable potential pitfall is that this condition may show elevated serum and tissue $\mathrm{IgG} 4$, and therefore, on histopathology, this disease represents one of the closest mimics of IgG4-related disease. ${ }^{90,91}$

Rheumatoid arthritis may rarely affect the pancreas. Patients typically present with a pancreatic mass lesion. Although most patients report a history of rheumatoid arthritis, the association between the systemic disease and the pancreatic mass is rarely suspected, and the diagnosis is made on the surgical resection. Histologically, the pancreas shows rheumatoid nodules, which are sometimes surrounded by relatively dense lymphoplasmacytic infiltration that may resemble autoimmune pancreatitis.

\section{Conclusions}

Mass-forming types of chronic pancreatitis represent a major challenge, given that they mimic the more common pancreatic neoplasm, pancreatic ductal adenocarcinoma. Incremental advances in the understanding of the clinical, imaging, and histologic features of these diseases have significantly reduced the number of pancreatic resections. Although clinical and radiological features are helpful, histology plays a critical role in defining these diseases, and more important, excluding pancreatic malignancy. The two most common such diseases, type 1 and type 2 autoimmune pancreatitis, share little in common other than a name. Investigations in the past decade have uncovered mechanisms that account for the unique histologic findings in autoimmune pancreatitis; however, little is yet known about the immunologic triggers of these diseases.

\section{Supplemental Data}

Supplemental material for this article can be found at https://doi.org/10.1016/j.ajpath.2018.05.022.

\section{References}

1. Yoshida K, Toki F, Takeuchi T, Watanabe S, Shiratori K, Hayashi N: Chronic pancreatitis caused by an autoimmune abnormality: proposal of the concept of autoimmune pancreatitis. Dig Dis Sci 1995, 40: $1561-1568$

2. Sarles H, Sarles JC, Muratore R, Guien C: Chronic inflammatory sclerosis of the pancreas: an autonomous pancreatic disease? Am J Dig Dis 1961, 6:688-698

3. Kawaguchi K, Koike M, Tsuruta K, Okamoto A, Tabata I, Fujita N: Lymphoplasmacytic sclerosing pancreatitis with cholangitis: a variant of primary sclerosing cholangitis extensively involving pancreas. Hum Pathol 1991, 22:387-395

4. Chung JP, Na SK, Park YN, Yu JS, Yoon DS, Lee SJ, Song SY, Lee KS, Chung JB, Lee SI, Kang JK: Non-alcoholic duct-destructive chronic pancreatitis: recognition before definitive treatment. Yonsei Med J 1999, 40:518-522

5. Van Hoe L, Gryspeerdt S, Ectors N, Van Steenbergen W, Aerts R, Baert AL, Marchal G: Nonalcoholic duct-destructive chronic pancreatitis: imaging findings. AJR Am J Roentgenol 1998, 170: 643-647

6. Wakabayashi T, Motoo Y, Kojima Y, Makino H, Sawabu N: Chronic pancreatitis with diffuse irregular narrowing of the main pancreatic duct. Dig Dis Sci 1998, 43:2415-2425

7. Ectors N, Maillet B, Aerts R, Geboes K, Donner A, Borchard F, Lankisch P, Stolte M, Luttges J, Kremer B, Kloppel G: Non-alcoholic duct destructive chronic pancreatitis. Gut 1997, 41:263-268

8. Hamano H, Kawa S, Horiuchi A, Unno H, Furuya N, Akamatsu T, Fukushima M, Nikaido T, Nakayama K, Usuda N, Kiyosawa K: High serum IgG4 concentrations in patients with sclerosing pancreatitis. N Engl J Med 2001, 344:732-738

9. Hamano H, Kawa S, Ochi Y, Unno H, Shiba N, Wajiki M, Nakazawa K, Shimojo H, Kiyosawa K: Hydronephrosis associated 
with retroperitoneal fibrosis and sclerosing pancreatitis. Lancet 2002, 359:1403-1404

10. Zen Y, Harada K, Sasaki M, Sato Y, Tsuneyama K, Haratake J, Kurumaya H, Katayanagi K, Masuda S, Niwa H, Morimoto H, Miwa A, Uchiyama A, Portmann BC, Nakanuma Y: IgG4-related sclerosing cholangitis with and without hepatic inflammatory pseudotumor, and sclerosing pancreatitis-associated sclerosing cholangitis: do they belong to a spectrum of sclerosing pancreatitis? Am J Surg Pathol 2004, 28:1193-1203

11. Zen Y, Fujii T, Sato Y, Masuda S, Nakanuma Y: Pathological classification of hepatic inflammatory pseudotumor with respect to IgG4related disease. Mod Pathol 2007, 20:884-894

12. Kitagawa S, Zen Y, Harada K, Sasaki M, Sato Y, Minato H, Watanabe K, Kurumaya H, Katayanagi K, Masuda S, Niwa H, Tsuneyama K, Saito K, Haratake J, Takagawa K, Nakanuma Y: Abundant IgG4-positive plasma cell infiltration characterizes chronic sclerosing sialadenitis (Kuttner's tumor). Am J Surg Pathol 2005, 29: 783-791

13. Geyer JT, Ferry JA, Harris NL, Stone JH, Zukerberg LR, Lauwers GY, Pilch BZ, Deshpande V: Chronic sclerosing sialadenitis (Kuttner tumor) is an IgG4-associated disease. Am J Surg Pathol 2010, 34:202-210

14. Ferry JA, Klepeis V, Sohani AR, Harris NL, Preffer FI, Stone JH, Grove A, Deshpande V: IgG4-related orbital disease and its mimics in a Western population. Am J Surg Pathol 2015, 39: $1688-1700$

15. Zen $\mathrm{Y}$, Inoue $\mathrm{D}$, Kitao A, Onodera M, Abo H, Miyayama S, Gabata T, Matsui O, Nakanuma Y: IgG4-related lung and pleural disease: a clinicopathologic study of 21 cases. Am J Surg Pathol 2009, 33:1886-1893

16. Cornell LD, Chicano SL, Deshpande V, Collins AB, Selig MK, Lauwers GY, Barisoni L, Colvin RB: Pseudotumors due to IgG4 immune-complex tubulointerstitial nephritis associated with autoimmune pancreatocentric disease. Am J Surg Pathol 2007, 31: $1586-1597$

17. Kasashima S, Zen Y, Kawashima A, Konishi K, Sasaki H, Endo M, Matsumoto Y, Kawakami K, Kasashima F, Moriya M, Kimura K, Ohtake H, Nakanuma Y: Inflammatory abdominal aortic aneurysm: close relationship to IgG4-related periaortitis. Am J Surg Pathol 2008, 32:197-204

18. Zen $\mathrm{Y}$, Onodera $\mathrm{M}$, Inoue $\mathrm{D}$, Kitao A, Matsui $\mathrm{O}$, Nohara $\mathrm{T}$, Namiki M, Kasashima S, Kawashima A, Matsumoto Y, Katayanagi K, Murata T, Ishizawa S, Hosaka N, Kuriki K, Nakanuma Y: Retroperitoneal fibrosis: a clinicopathologic study with respect to immunoglobulin G4. Am J Surg Pathol 2009, 33: $1833-1839$

19. Khosroshahi A, Carruthers MN, Stone JH, Shinagare S, Sainani N, Hasserjian RP, Deshpande V: Rethinking Ormond's disease: "idiopathic" retroperitoneal fibrosis in the era of IgG4-related disease. Medicine 2013, 92:82-91

20. Stone JH, Zen Y, Deshpande V: IgG4-related disease. N Engl J Med 2012, 366:539-551

21. Kamisawa T, Funata N, Hayashi Y, Tsuruta K, Okamoto A, Amemiya K, Egawa N, Nakajima H: Close relationship between autoimmune pancreatitis and multifocal fibrosclerosis. Gut 2003, 52: 683-687

22. Inoue D, Yoshida K, Yoneda N, Ozaki K, Matsubara T, Nagai K, Okumura K, Toshima F, Toyama J, Minami T, Matsui O, Gabata T, Zen Y: IgG4-related disease: dataset of 235 consecutive patients. Medicine 2015, 94:e680

23. Zamboni G, Luttges J, Capelli P, Frulloni L, Cavallini G, Pederzoli P, Leins A, Longnecker D, Kloppel G: Histopathological features of diagnostic and clinical relevance in autoimmune pancreatitis: a study on 53 resection specimens and 9 biopsy specimens. Virchows Arch 2004, 445:552-563

24. Notohara K, Burgart LJ, Yadav D, Chari S, Smyrk TC: Idiopathic chronic pancreatitis with periductal lymphoplasmacytic infiltration: clinicopathologic features of 35 cases. Am J Surg Pathol 2003, 27 : $1119-1127$

25. Zhang L, Notohara K, Levy MJ, Chari ST, Smyrk TC: IgG4-positive plasma cell infiltration in the diagnosis of autoimmune pancreatitis. Mod Pathol 2007, 20:23-28

26. Zhang L, Chari S, Smyrk TC, Deshpande V, Kloppel G, Kojima M, Liu X, Longnecker DS, Mino-Kenudson M, Notohara K, RodriguezJusto M, Srivastava A, Zamboni G, Zen Y: Autoimmune pancreatitis (AIP) type 1 and type 2: an international consensus study on histopathologic diagnostic criteria. Pancreas 2011, 40:1172-1179

27. Kloppel G, Detlefsen S, Chari ST, Longnecker DS, Zamboni G: Autoimmune pancreatitis: the clinicopathological characteristics of the subtype with granulocytic epithelial lesions. J Gastroenterol 2010, 45:787-793

28. Park DH, Kim MH, Chari ST: Recent advances in autoimmune pancreatitis. Gut 2009, 58:1680-1689

29. Shimosegawa T, Chari ST, Frulloni L, Kamisawa T, Kawa S, MinoKenudson M, Kim MH, Kloppel G, Lerch MM, Lohr M, Notohara K, Okazaki K, Schneider A, Zhang L; International Association of Pancreatology: International consensus diagnostic criteria for autoimmune pancreatitis: guidelines of the International Association of Pancreatology. Pancreas 2011, 40:352-358

30. Kamisawa T, Chari ST, Lerch MM, Kim MH, Gress TM, Shimosegawa T: Recent advances in autoimmune pancreatitis: type 1 and type 2. Gut 2013, 62:1373-1380

31. Hart PA, Zen Y, Chari ST: Recent advances in autoimmune pancreatitis. Gastroenterology 2015, 149:39-51

32. Hart PA, Kamisawa T, Brugge WR, Chung JB, Culver EL, Czako L, Frulloni L, Go VL, Gress TM, Kim MH, Kawa S, Lee KT, Lerch MM, Liao WC, Lohr M, Okazaki K, Ryu JK, Schleinitz N, Shimizu K, Shimosegawa T, Soetikno R, Webster G, Yadav D, Zen Y, Chari ST: Long-term outcomes of autoimmune pancreatitis: a multicentre, international analysis. Gut 2013, 62:1771-1776

33. Kawa S, Ota M, Yoshizawa K, Horiuchi A, Hamano H, Ochi Y, Nakayama K, Tokutake Y, Katsuyama Y, Saito S, Hasebe O, Kiyosawa K: HLA DRB10405-DQB10401 haplotype is associated with autoimmune pancreatitis in the Japanese population. Gastroenterology 2002, 122:1264-1269

34. Umemura T, Ota M, Hamano H, Katsuyama Y, Muraki T, Arakura N, Kawa S, Kiyosawa K: Association of autoimmune pancreatitis with cytotoxic T-lymphocyte antigen 4 gene polymorphisms in Japanese patients. Am J Gastroenterol 2008, 103:588-594

35. Umemura $\mathrm{T}$, Ota M, Hamano H, Katsuyama $\mathrm{Y}$, Kiyosawa $\mathrm{K}$, Kawa S: Genetic association of Fc receptor-like 3 polymorphisms with autoimmune pancreatitis in Japanese patients. Gut 2006, 55: $1367-1368$

36. Okazaki K, Uchida K, Ohana M, Nakase H, Uose S, Inai M, Matsushima Y, Katamura K, Ohmori K, Chiba T: Autoimmunerelated pancreatitis is associated with autoantibodies and a Th1/Th2type cellular immune response. Gastroenterology 2000, 118:573-581

37. Aparisi L, Farre A, Gomez-Cambronero L, Martinez J, De Las Heras G, Corts J, Navarro S, Mora J, Lopez-Hoyos M, Sabater L, Ferrandez A, Bautista D, Perez-Mateo M, Mery S, Sastre J: Antibodies to carbonic anhydrase and IgG4 levels in idiopathic chronic pancreatitis: relevance for diagnosis of autoimmune pancreatitis. Gut 2005, 54:703-709

38. Lohr JM, Faissner R, Koczan D, Bewerunge P, Bassi C, Brors B, Eils R, Frulloni L, Funk A, Halangk W, Jesenofsky R, Kaderali L, Kleeff J, Kruger B, Lerch MM, Losel R, Magnani M, Neumaier M, Nittka S, Sahin-Toth M, Sanger J, Serafini S, Schnolzer M, Thierse HJ, Wandschneider S, Zamboni G, Kloppel G: Autoantibodies against the exocrine pancreas in autoimmune pancreatitis: gene and protein expression profiling and immunoassays identify pancreatic enzymes as a major target of the inflammatory process. Am J Gastroenterol 2010, 105:2060-2071

39. Frulloni L, Lunardi C, Simone R, Dolcino M, Scattolini C, Falconi M, Benini L, Vantini I, Corrocher R, Puccetti A 
Identification of a novel antibody associated with autoimmune pancreatitis. N Engl J Med 2009, 361:2135-2142

40. de Buy Wenniger LJ, Culver EL, Beuers U: Exposure to occupational antigens might predispose to IgG4-related disease. Hepatology 2014, 60:1453-1454

41. Shiokawa M, Kodama Y, Yoshimura K, Kawanami C, Mimura J, Yamashita Y, Asada M, Kikuyama M, Okabe Y, Inokuma T, Ohana M, Kokuryu H, Takeda K, Tsuji Y, Minami R, Sakuma Y, Kuriyama K, Ota Y, Tanabe W, Maruno T, Kurita A, Sawai Y, Uza N, Watanabe T, Haga H, Chiba T: Risk of cancer in patients with autoimmune pancreatitis. Am J Gastroenterol 2013, 108:610-617

42. Zen Y, Fujii T, Harada K, Kawano M, Yamada K, Takahira M, Nakanuma Y: Th2 and regulatory immune reactions are increased in immunoglobin G4-related sclerosing pancreatitis and cholangitis. Hepatology 2007, 45:1538-1546

43. Sah RP, Pannala R, Zhang L, Graham RP, Sugumar A, Chari ST: Eosinophilia and allergic disorders in autoimmune pancreatitis. Am J Gastroenterol 2010, 105:2485-2491

44. Miyoshi H, Uchida K, Taniguchi T, Yazumi S, Matsushita M, Takaoka M, Okazaki K: Circulating naive and CD4+CD25high regulatory T cells in patients with autoimmune pancreatitis. Pancreas 2008, 36:133-140

45. Jeannin P, Lecoanet S, Delneste Y, Gauchat JF, Bonnefoy JY: IgE versus IgG4 production can be differentially regulated by IL-10. J Immunol 1998, 160:3555-3561

46. Mattoo H, Mahajan VS, Maehara T, Deshpande V, Della-Torre E, Wallace ZS, Kulikova M, Drijvers JM, Daccache J, Carruthers MN, Castelino FV, Stone JR, Stone JH, Pillai S: Clonal expansion of CD4(+) cytotoxic T lymphocytes in patients with IgG4-related disease. J Allergy Clin Immunol 2016, 138:825-838

47. Akiyama M, Suzuki K, Yasuoka H, Kaneko Y, Yamaoka K, Takeuchi T: Follicular helper T cells in the pathogenesis of IgG4related disease. Rheumatology (Oxford) 2018, 57:236-245

48. Akiyama M, Yasuoka H, Yamaoka K, Suzuki K, Kaneko Y, Kondo H, Kassai Y, Koga K, Miyazaki T, Morita R, Yoshimura A, Takeuchi T: Enhanced IgG4 production by follicular helper $2 \mathrm{~T}$ cells and the involvement of follicular helper $1 \mathrm{~T}$ cells in the pathogenesis of IgG4-related disease. Arthritis Res Ther 2016, 18:167

49. Kubo M: T follicular helper and $\mathrm{TH} 2$ cells in allergic responses. Allergol Int 2017, 66:377-381

50. Zen Y, Nakanuma Y: IgG4-related disease: a cross-sectional study of 114 cases. Am J Surg Pathol 2010, 34:1812-1819

51. Hart PA, Topazian MD, Witzig TE, Clain JE, Gleeson FC, Klebig RR, Levy MJ, Pearson RK, Petersen BT, Smyrk TC, Sugumar A, Takahashi N, Vege SS, Chari ST: Treatment of relapsing autoimmune pancreatitis with immunomodulators and rituximab: the Mayo Clinic experience. Gut 2013, 62:1607-1615

52. Mattoo H, Mahajan VS, Della-Torre E, Sekigami Y, Carruthers M, Wallace ZS, Deshpande V, Stone JH, Pillai S: De novo oligoclonal expansions of circulating plasmablasts in active and relapsing IgG4-related disease. J Allergy Clin Immunol 2014, 134:679-687

53. Maillette de Buy Wenniger LJ, Doorenspleet ME, Klarenbeek PL, Verheij J, Baas F, Elferink RP, Tak PP, de Vries N, Beuers U: Immunoglobulin G4+ clones identified by next-generation sequencing dominate the B cell receptor repertoire in immunoglobulin G4 associated cholangitis. Hepatology 2013, 57:2390-2398

54. Aalberse RC, Stapel SO, Schuurman J, Rispens T: Immunoglobulin G4: an odd antibody. Clin Exp Allergy 2009, 39:469-477

55. van der Neut Kolfschoten M, Schuurman J, Losen M, Bleeker WK, Martinez-Martinez P, Vermeulen E, den Bleker TH, Wiegman L, Vink T, Aarden LA, De Baets MH, van de Winkel JG, Aalberse RC, Parren PW: Anti-inflammatory activity of human IgG4 antibodies by dynamic Fab arm exchange. Science 2007, 317:1554-1557

56. Shiokawa M, Kodama Y, Kuriyama K, Yoshimura K, Tomono T, Morita T, Kakiuchi N, Matsumori T, Mima A, Nishikawa Y, Ueda T, Tsuda M, Yamauchi Y, Minami R, Sakuma Y, Ota Y, Maruno T,
Kurita A, Sawai Y, Tsuji Y, Uza N, Matsumura K, Watanabe T, Notohara K, Tsuruyama T, Seno H, Chiba T: Pathogenicity of IgG in patients with IgG4-related disease. Gut 2016, 65:1322-1332

57. Zen Y, Britton D, Mitra V, Pike I, Heaton N, Quaglia A: A global proteomic study identifies distinct pathological features of IgG4related and primary sclerosing cholangitis. Histopathology 2016, 68:796-809

58. Hart PA, Levy MJ, Smyrk TC, Takahashi N, Abu Dayyeh BK, Clain JE, Gleeson FC, Pearson RK, Petersen BT, Topazian MD, Vege SS, Zhang L, Chari ST: Clinical profiles and outcomes in idiopathic duct-centric chronic pancreatitis (type 2 autoimmune pancreatitis): the Mayo Clinic experience. Gut 2016, 65:1702-1709

59. Ku Y, Hong SM, Fujikura K, Kim SJ, Akita M, Abe-Suzuki S, Shiomi H, Masuda A, Itoh T, Azuma T, Kim MH, Zen Y: IL-8 expression in granulocytic epithelial lesions of idiopathic duct-centric pancreatitis (type 2 autoimmune pancreatitis). Am J Surg Pathol 2017, 41:1129-1138

60. Sah RP, Chari ST, Pannala R, Sugumar A, Clain JE, Levy MJ, Pearson RK, Smyrk TC, Petersen BT, Topazian MD, Takahashi N, Farnell MB, Vege SS: Differences in clinical profile and relapse rate of type 1 versus type 2 autoimmune pancreatitis. Gastroenterology 2010, 139:140-148

61. Deshpande V, Chicano S, Finkelberg D, Selig MK, MinoKenudson M, Brugge WR, Colvin RB, Lauwers GY: Autoimmune pancreatitis: a systemic immune complex mediated disease. Am J Surg Pathol 2006, 30:1537-1545

62. Deshpande V, Gupta R, Sainani N, Sahani DV, Virk R, Ferrone C, Khosroshahi A, Stone JH, Lauwers GY: Subclassification of autoimmune pancreatitis: a histologic classification with clinical significance. Am J Surg Pathol 2011, 35:26-35

63. Finkelberg DL, Sahani D, Deshpande V, Brugge WR: Autoimmune pancreatitis. N Engl J Med 2006, 355:2670-2676

64. Deshpande V, Mino-Kenudson M, Brugge W, Lauwers GY: Autoimmune pancreatitis: more than just a pancreatic disease? a contemporary review of its pathology. Arch Pathol Lab Med 2005, 129: $1148-1154$

65. Scheers I, Palermo JJ, Freedman S, Wilschanski M, Shah U, Abu-ElHaija M, Barth B, Fishman DS, Gariepy C, Giefer MJ, Heyman MB, Himes RW, Husain SZ, Lin TK, Liu Q, Lowe M, Mascarenhas M, Morinville V, Ooi CY, Perito ER, Piccoli DA, Pohl JF, Schwarzenberg SJ, Troendle D, Werlin S, Zimmerman B, Uc A, Gonska T: Autoimmune pancreatitis in children: characteristic features, diagnosis, and management. Am J Gastroenterol 2017, 112: $1604-1611$

66. Zen Y, Grammatikopoulos T, Hadzic N: Autoimmune pancreatitis in children: insights into the diagnostic challenge. J Pediatr Gastroenterol Nutr 2014, 59:e42-e45

67. Notohara K, Nishimori I, Mizuno N, Okazaki K, Ito T, Kawa S, Egawa S, Kihara Y, Kanno A, Masamune A, Shimosegawa T: Clinicopathological features of type 2 autoimmune pancreatitis in Japan: results of a multicenter survey. Pancreas 2015, 44:1072-1077

68. Sahani DV, Sainani NI, Deshpande V, Shaikh MS, Frinkelberg DL, Fernandez-del Castillo C: Autoimmune pancreatitis: disease evolution, staging, response assessment, and CT features that predict response to corticosteroid therapy. Radiology 2009, 250:118-129

69. Sugumar A, Levy MJ, Kamisawa T, Webster GJ, Kim MH, Enders F, Amin Z, Baron TH, Chapman MH, Church NI, Clain JE, Egawa N, Johnson GJ, Okazaki K, Pearson RK, Pereira SP, Petersen BT, Read S, Sah RP, Sandanayake NS, Takahashi N, Topazian MD, Uchida K, Vege SS, Chari ST: Endoscopic retrograde pancreatography criteria to diagnose autoimmune pancreatitis: an international multicentre study. Gut 2011, 60:666-670

70. Deshpande V, Zen Y, Chan JKC, Yi EE, Sato Y, Yoshino T, et al: Consensus statement on the pathology of IgG4-related disease. Mod Pathol 2012, 25:1181-1192

71. Deshpande V: The pathology of IgG4-related disease: critical issues and challenges. Semin Diagn Pathol 2012, 29:191-196 
72. Farris AB 3rd, Lauwers GY, Deshpande V: Autoimmune pancreatitisrelated diabetes: quantitative analysis of endocrine islet cells and inflammatory infiltrate. Virchows Arch 2010, 457:329-336

73. Chen JH, Deshpande V: IgG4-related disease and the liver. Gastroenterol Clin North Am 2017, 46:195-216

74. Strehl JD, Hartmann A, Agaimy A: Numerous IgG4-positive plasma cells are ubiquitous in diverse localised non-specific chronic inflammatory conditions and need to be distinguished from IgG4-related systemic disorders. J Clin Pathol 2011, 64:237-243

75. Hart PA, Smyrk TC, Chari ST: Lymphoplasmacytic sclerosing pancreatitis without IgG4 tissue infiltration or serum IgG4 elevation: IgG4-related disease without IgG4. Mod Pathol 2015, 28:238-247

76. Okazaki K, Chari ST, Frulloni L, Lerch MM, Kamisawa T, Kawa S, Kim MH, Levy P, Masamune A, Webster G, Shimosegawa T: International consensus for the treatment of autoimmune pancreatitis. Pancreatology 2017, 17:1-6

77. Ngwa T, Law R, Hart P, Smyrk TC, Chari ST: Serum IgG4 elevation in pancreatic cancer: diagnostic and prognostic significance and association with autoimmune pancreatitis. Pancreas 2015, 44:557-560

78. Pak LM, Schattner MA, Balachandran V, D'Angelica MI, DeMatteo RP, Kingham TP, Jarnagin WR, Allen PJ: The clinical utility of immunoglobulin G4 in the evaluation of autoimmune pancreatitis and pancreatic adenocarcinoma. HPB (Oxford) 2018, 20: $182-187$

79. Kamisawa T, Shimosegawa T, Okazaki K, Nishino T, Watanabe H, Kanno A, Okumura F, Nishikawa T, Kobayashi K, Ichiya T, Takatori H, Yamakita K, Kubota K, Hamano H, Okamura K, Hirano K, Ito T, Ko SB, Omata M: Standard steroid treatment for autoimmune pancreatitis. Gut 2009, 58:1504-1507

80. Gupta R, Khosroshahi A, Shinagare S, Fernandez C, Ferrone C, Lauwers GY, Stone JH, Deshpande V: Does autoimmune pancreatitis increase the risk of pancreatic carcinoma? a retrospective analysis of pancreatic resections. Pancreas 2013, 42:506-510

81. Gupta RK, Xie BH, Patton KT, Lisovsky M, Burks E, Behrman SW, Klimstra D, Deshpande V: Follicular pancreatitis: a distinct form of chronic pancreatitis: an additional mimic of pancreatic neoplasms. Hum Pathol 2016, 48:154-162
82. Mizuuchi Y, Aishima S, Hattori M, Ushijima Y, Aso A, Takahata S, Ohtsuka T, Ueda J, Tanaka M, Oda Y: Follicular pancreatitis, report of a case clinically mimicking pancreatic cancer and literature review. Pathol Res Pract 2014, 210:118-122

83. Zen Y, Ishikawa A, Ogiso S, Heaton N, Portmann B: Follicular cholangitis and pancreatitis: clinicopathological features and differential diagnosis of an under-recognized entity. Histopathology 2012, 60:261-269

84. Hatzitheoklitos E, Buchler MW, Friess H, DiSebastiano P, Poch B, Beger HG, Mohr W: Pseudolymphoma of the pancreas mimicking cancer. Pancreas 1994, 9:668-670

85. Nakashiro $\mathrm{H}$, Tokunaga $\mathrm{O}$, Watanabe $\mathrm{T}$, Ishibashi $\mathrm{K}$, Kuwaki $\mathrm{T}$ : Localized lymphoid hyperplasia (pseudolymphoma) of the pancreas presenting with obstructive jaundice. Hum Pathol 1991, 22: 724-726

86. Zen Y, Nakanuma Y, Portmann B: Immunoglobulin G4-related sclerosing cholangitis: pathologic features and histologic mimics. Semin Diagn Pathol 2012, 29:205-211

87. Kemp JA, Arora S, Fawaz K: Recurrent acute pancreatitis as a manifestation of Wegener's granulomatosis. Dig Dis Sci 1990, 35: 912-915

88. Matsubayashi H, Seki T, Niki S, Mizumura Y, Taguchi Y, Moriyasu F, Go K: Wegener's granulomatosis with onset of acute pancreatitis and rapid progress: a case report. Pancreatology 2001, 1: 263-266

89. Valerieva Y, Golemanov B, Tzolova N, Mitova R: Pancreatic mass as an initial presentation of severe Wegener's granulomatosis. Ann Gastroenterol 2013, 26:267-269

90. Chang SY, Keogh KA, Lewis JE, Ryu JH, Cornell LD, Garrity JA, Yi ES: IgG4-positive plasma cells in granulomatosis with polyangiitis (Wegener's): a clinicopathologic and immunohistochemical study on 43 granulomatosis with polyangiitis and 20 control cases. Hum Pathol 2013, 44:2432-2437

91. Byrne TN, Stone JH, Pillai SS, Rapalino O, Deshpande V: Case records of the Massachusetts General Hospital: case 31-2016: a 53year-old man with diplopia, polydipsia, and polyuria. N Engl J Med 2016, 375:1469-1480 